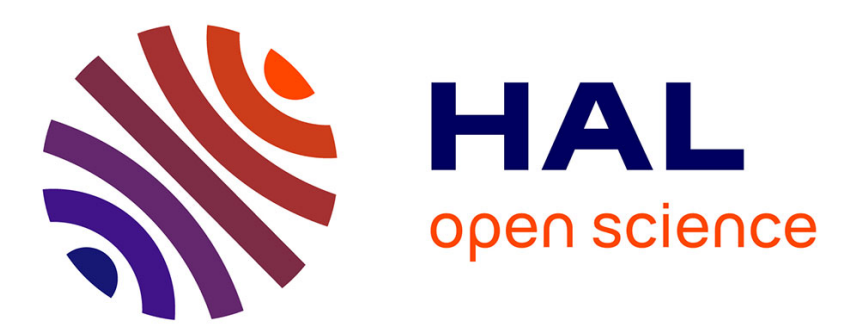

\title{
Impact on retail prices of non-neutral wholesale prices for content providers
}

Giuseppe d'Acquisto, Patrick Maillé, Maurizio Naldi, Bruno Tuffin

\section{To cite this version:}

Giuseppe d'Acquisto, Patrick Maillé, Maurizio Naldi, Bruno Tuffin. Impact on retail prices of nonneutral wholesale prices for content providers. NGI 2012: 8th Euro-NF Conference on Next Generation Internet, Jun 2012, Karlskrona, Sweden. pp.111-117. hal-00725050

\section{HAL Id: hal-00725050 \\ https://hal.science/hal-00725050}

Submitted on 23 Aug 2012

HAL is a multi-disciplinary open access archive for the deposit and dissemination of scientific research documents, whether they are published or not. The documents may come from teaching and research institutions in France or abroad, or from public or private research centers.
L'archive ouverte pluridisciplinaire HAL, est destinée au dépôt et à la diffusion de documents scientifiques de niveau recherche, publiés ou non, émanant des établissements d'enseignement et de recherche français ou étrangers, des laboratoires publics ou privés. 


\title{
Impact on retail prices of non-neutral wholesale prices for content providers
}

\author{
Giuseppe D’Acquisto*, Patrick Maillé ${ }^{\dagger}$, Maurizio Naldi ${ }^{\ddagger}$, and Bruno Tuffin ${ }^{\S}$ \\ * Garante per la protezione dei dati personali \\ Roma, Italy \\ Email: g.dacquisto@garanteprivacy.it \\ $\dagger$ TELECOM Bretagne \\ 2, Cesson Sévigné, France \\ Email: patrick.maille@telecom-bretagne.eu \\ †Università di Roma Tor Vergata \\ Roma, Italy \\ Email: naldi@disp.uniroma2.it \\ $\S$ INRIA Rennes - Bretagne Atlantique \\ Rennes, France \\ Email: bruno.tuffin@irisa.fr
}

\begin{abstract}
The impact of wholesale prices is examined in a context where the end customer access both free content and payper-use content, delivered by two different providers through a common network provider. We formulate and solve the game between the network provider and the pay-per-use content provider, where both use the price they separately charge the end customer with as a leverage to maximize their profits. In the neutral case (the network provider charges equal wholesale prices to the two content providers), the benefits coming from wholesale price reductions are largely retained by the pay-peruse content provider. When the free content provider is charged more than its pay-per-use competitor, both the network provider and the pay-per-use content provider see their profit increase, while the end customer experiences a negligible reduction in the retail price.
\end{abstract}

\section{INTRODUCTION}

In the recent years, the Internet has become a major medium for content delivery, to an extent that destabilizes the traditional supply and delivery chains for entertainment and news contents. As a result, the sale and delivery of multimedia content through the Internet keeps increasing, the most famous example being the video-on-demand provider Netflix, whose revenue increased by $29 \%$ in 2010 , and by around $40 \%$ in 2011. But the corresponding traffic load grew accordingly: with $30 \%$ of total traffic in the US, Netflix now represents more traffic than the popular peer-to-peer BitTorrent [11].

Content providers use the Internet as a delivery means, however they are charged only by the Internet Service Provider (ISP) they are directly connected to, who may adapt the connection price to the treated traffic. On the other hand, most consumers subscribe to an ISP that is not one of the content providers, so that their ISP has to relay the traffic issued by content providers without being paid by the latter. When ISPs are connected through transit agreements, this asymmetry can be compensated by transit fees: the ISPs providing access to the major sources of traffic pay more than those whose customers are mainly traffic sinks. Instead, when connections between ISPs are established so that neither party pays the other for the exchanged traffic (the sender keeps all agreement that is known as peering [5]), the ISPs who count big content providers among their clients appear as free-riders for the other ISPs, with ensuing strains on the business model.

A possibility to solve that issue, advocated by some major ISPs, is that content providers be directly charged by all ISPs serving their flows, and not only by their access provider, through some so-called side payments. A mounting pressure towards that direction comes from ISPs, and overflows on regulators [10]. Though negated by ISPs, such a solution may appear to contradict the network neutrality principle, stating that all packets in the network should be treated equally, independently of their origin, destination, or associated application [3]. Also, the unit price may be different for different content providers, spurring additional neutrality issues: one of the content providers may have a preferred commercial liaison with the ISP and get better prices. The position of many content providers is to forbid such side payments, that would endanger their survival and harm their ability to create content, which will also favor the illegal exchange of content. On the other hand, ISPs claim that such payments are necessary for them to continue improving the quality of service by investing in network expansions.

The problem of side-payments in the context of Network Neutrality has recently been studied quite extensively. In [4], only one (pay-per-use) content provider is considered, and it is claimed that ISPs are right to ask for a fairer share of the overall revenues, but that this cannot be achieved through side payments. In [6], [7], the focus is on revenue sharing rules among stakeholders, while the use of side-payments as a tool to reach such a sharing should also be investigated. In particular, the identity and the objectives of the price setter for those payments is likely to have a major role, as we can 
imagine side-payments to be decided by a regulator in order to favor users, or by one network stakeholder trying to optimize revenue. The effect of side payments is also investigated in [8], where their effect in terms of investment incentives for ISPs is shown to be positive.

Though this picture may appear as a case of competition between the two classes of content providers, or between the content providers and the ISPs, an often neglected stakeholder is the end customer, who should instead be protected by the legislation. In fact, any policy taken by the ISPs and the content providers provokes consequences on the end customers, through the variety of accessible content and the prices paid.

In this paper, we analyse how changes in the wholesale prices (i.e., the charges levied on the content providers) are transferred to the end customer, and we assess how deviations from the neutral approach affect the retail prices asked of the end customer. Namely, we consider the case of two archetypal content providers, who deliver their content respectively free of charge and on a pay-per-use basis. The end customer accesses their services through its ISP. In the solution based on side payments, both content providers are charged per volume by that ISP. We consider the charging policy by the ISP to be neutral if the unit prices charged to the two content providers are equal, and non-neutral otherwise.

We formulate the strategical decisions taken by the ISP and the pay-per-use content provider as a game, where the two players use the unit price imposed on the end customer as their leverage to maximize their surplus. We find that, for the wide range of cases examined, the game always exhibits a single Nash equilibrium. In the neutral case, the ISP may be forced to reduce its wholesale prices to favour access to content. However, we find that the end customer is barely affected by such price reductions: for each percent reduction in the wholesale price, the overall retail price paid by the customer decreases by no more than 0.2 percent roughly. The benefit of wholesale price reductions is largely retained by the pay-per-use content provider. At the same time, in the nonneutral case (higher prices for the free content provider), the pay-per-use content provider is largely favoured, with its profit increasing linearly with the wholesale price for the free content provider. However, the overall effect on the end customer is negligible, but in the wrong direction. When the wholesale price for the free content provider doubles, the price paid by the end customer increases as well, though by less than $3 \%$. This raises the suspicion that the ISP and the pay-per-use content provider may be induced into a colluding behaviour without the end customer directly perceiving it, a situation that should be further investigated.

\section{PROVIDERS AND PAYMENT FLOWS}

Several stakeholders play a role in the provision of content to end customers. In this section, we describe the roles played by the most important actors, and provide a model for their interactions.

We consider two content providers: a provider $F$ of free content, and a provider $P$ of pay-per-use content. A customer
$U$ retrieves the contents provided by $F$ and $P$ through the network operator $N$. In the following, we refer to a single customer, representative of the collective behaviour of all the customers.

The content providers pay the network operator for the use of the network backbone. The payment is proportional to the volume of traffic delivered by the two content providers, but the unit price may be different. Namely, $F$ pays a price $t_{\mathrm{F}}$ per volume unit; and provider $P$ pays a unit price $t_{\mathrm{P}}$. If $t_{\mathrm{F}} \neq t_{\mathrm{P}}$, we consider that the network operator is applying a non-neutral pricing policy.

The content provider $F$ provides free content, and receives no money from its customers. The content provider $P$ receives instead an amount of money $p_{S}$ from its customers for each unit of traffic delivered. Both content providers benefit from advertisement, receiving respectively the unit revenues $v_{F}$ and $v_{P}$.

On the other hand, the customer $U$ pays both the network operator and the content provider $P$. It pays the network operator to access the network, through a two-part tariffing scheme. That tariffing scheme includes a fixed fee $a$ plus a volumeproportional variable component. The price per unit volume is $p_{\mathrm{N}}$. In addition, it pays the content provider $P$ a price $p_{S}$ per unit volume. If we indicate by $D_{P}$ and by $D_{F}$ the traffic delivered respectively by the content provider $P$ and by $F$, the overall expense by the user is $a+p_{N}\left(D_{P}+D_{F}\right)+p_{S} D_{P}$.

While the total charges depend on the demand levels $D_{P}$ and $D_{F}$, those demand levels are in turn determined by the prices through the following demand functions, inspired by [2]:

$$
\begin{aligned}
& D_{P}=D_{0, P} \max \left[1-\alpha\left(p_{S}+p_{N}\right)+\beta p_{N}, 0\right] \\
& D_{F}=D_{0, F} \max \left[1-\hat{\alpha} p_{N}+\hat{\beta}\left(p_{S}+p_{N}\right), 0\right],
\end{aligned}
$$

with $\alpha, \beta, \hat{\alpha}, \hat{\beta}>0$ to illustrate that a price decrease (resp. increase) at a given content provider will result in a demand increase (resp. decrease) at this provider, and demand decrease (resp. increase) at the opponent. In those equations, we employ the maximum operator to ensure that the demand function provides a non-negative value.

We also assume, that a uniform price increase in any of the two alternatives between $P$ and $F$ (i.e., increasing from the same level $p_{N}$, paid for each unit of free content volume, and $p_{N}+p_{S}$, paid for each unit of pay-per-use content volume) cannot result in an increase of demand level for any of the two players. In mathematical terms, this is expressed by the following constraint:

$$
\alpha>\beta \text { and } \hat{\alpha}>\hat{\beta}
$$

Finally, it is of practical value to assume that a price increase by a given provider cannot result in an increase of the total demand volume, which can be translated on the coefficients into

$$
\alpha D_{0, P}>\hat{\beta} D_{0, F} \text { and } \hat{\alpha} D_{0, F}>\hat{\beta} D_{0, F}+\beta D_{0, P},
$$




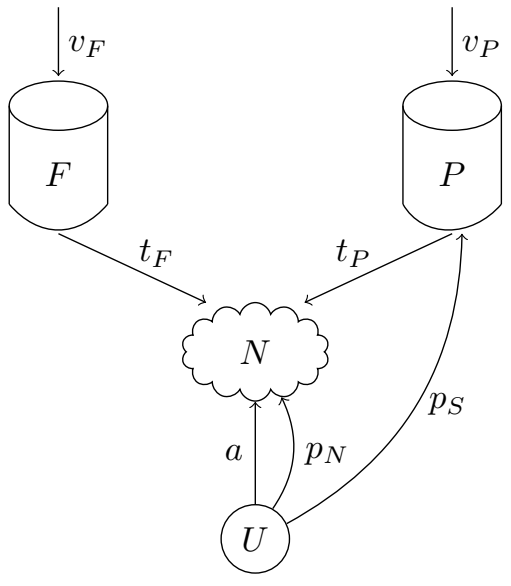

Fig. 1. Flows of payments. All prices are per unit of flow, except the per-user subscription price $a$.

by summing the two demand functions and looking at the conditions under which the derivatives with respect to $p_{N}$ and $p_{S}$ are negative.

We can also see the conditions for zeroing the demand. The demand for paid services becomes zero when the following condition is satisfied:

$$
1-\alpha p_{S}-(\alpha-\beta) p_{N} \leq 0 \Leftrightarrow p_{N} \geq \frac{1-\alpha p_{S}}{\alpha-\beta} .
$$

This gives the upper bound

$$
p_{N}^{P}=\frac{1-\alpha p_{S}}{\alpha-\beta} .
$$

On the other hand the demand for free services goes to zero when the price paid to the network operator is so large that

$$
1-\hat{\alpha} p_{N}+\hat{\beta}\left(p_{S}+p_{N}\right) \leq 0 \Leftrightarrow p_{N} \geq \frac{1+\hat{\beta} p_{S}}{\hat{\alpha}-\hat{\beta}} .
$$

This gives the upper bound

$$
p_{N}^{F}=\frac{1+\hat{\beta} p_{S}}{\hat{\alpha}-\hat{\beta}} .
$$

Through the services provided by the two content providers, the network provider receives money from three sources: the customer, and the two content providers. All the flows of money described in this section are shown in Fig. 1.

At the same time, both the content providers and the network operator experience operational expenses (OPEX), assumed to be proportional to the amount of delivered traffic. The unit OPEX for the two content providers are respectively $s_{F}$ and $s_{P}$. On the other hand, the network operator has to pay the operational expenses related to the transport backbone (which links the two content providers to it) and to the access link. Its unit OPEX are $n_{F}, n_{P}$ (costs per unit volume due to the transport of $F$ and $P$ traffic, respectively), and $k$ (cost per unit volume due to the access link). Note that $n_{F}$ and $n_{P}$ are costs per unit volume, while $k$ is a cost per customer.
As a result, we can write the profit of the network operator

$\Pi_{N}=a-k+p_{N}\left(D_{F}+D_{P}\right)+\left(t_{P}-n_{P}\right) D_{P}+\left(t_{F}-n_{F}\right) D_{F}$.

Instead, for the content provider $P$ we have the profit

$$
\Pi_{P}=\left(p_{S}+v_{P}-t_{P}-s_{P}\right) D_{P} .
$$

\section{THE PRICING GAME}

The two players, $P$ and $N$, aim at maximizing their respective profit, non-cooperatively. The content provider $P$ plays by using the unit price $p_{S}$ as its leverage, while the network operator $N$ acts on $p_{N}$. This game is played while the other parameters are fixed. The goal is to determine an equilibrium situation when no provider can increase its profit by unilaterally changing its price. This type of equilibrium is called a Nash equilibrium [9].

In order to find a Nash equilibrium, we first compute the best-response function of each provider, that is, the function giving the price value(s) maximizing the profit of the considered provider, defined in terms of the price strategy of the opponent. Formally:

$$
\begin{aligned}
& \operatorname{BR}_{N}\left(p_{S}\right)=\arg \max _{p_{N} \geq 0} \Pi_{N}\left(p_{N}, p_{S}\right) \\
& \operatorname{BR}_{P}\left(p_{N}\right)=\arg \max _{p_{S} \geq 0} \Pi_{S}\left(p_{N}, p_{S}\right) .
\end{aligned}
$$

A Nash equilibrium is simply a point $\left(p_{N}^{*}, p_{S}^{*}\right)$ for which $\operatorname{BR}_{N}\left(p_{S}^{*}\right)=p_{N}^{*}$ (or $p_{N}^{*} \in \mathrm{BR}_{N}\left(p_{S}^{*}\right)$ if it is made of several solutions) and equivalently $\operatorname{BR}_{P}\left(p_{N}^{*}\right)=p_{S}^{*}$. Graphically, if we draw the two best response curves on the same figure, the set of Nash equilibria is then the (possibly empty) set of intersection points of those curves.

The following propositions give the best-response functions of $P$ and $N$ in terms of the price of the opponent.

Proposition 1. The best-response function $B R_{P}$ of content provider $P$ is:

$$
B R_{P}\left(p_{N}\right)=\max \left(0, \frac{1+(\beta-\alpha) p_{N}-\alpha\left(v_{p}-t_{P}-s_{P}\right)}{2 \alpha}\right) .
$$

Proof: Recall from Equation (8) that the profit of the content provider $P$ is

$\Pi_{P}=\left(p_{S}+v_{P}-t_{P}-s_{P}\right) D_{0, P} \max \left[0,1-\alpha\left(p_{S}+p_{N}\right)+\beta p_{N}\right]$.

The upper bound (3) for the price $p_{N}$ giving a null demand also shows that $\Pi_{P}=0$ if $p_{S} \geq p_{S, \max }:=\frac{1-(\alpha-\beta) p_{N}}{\alpha}$. When $p_{S}$ is less than $p_{S, \max }$

$$
\begin{aligned}
\frac{\partial \Pi_{P}}{\partial p_{S}} & =D_{0, P}\left[1-\alpha\left(2 p_{S}+p_{N}+v_{P}-t_{P}-s_{P}\right)+\beta p_{N}\right] \\
& =D_{0, P}\left[1+(\beta-\alpha) p_{N}-\alpha\left(v_{p}-t_{P}-s_{P}\right)-2 \alpha p_{S}\right]
\end{aligned}
$$

This derivative is increasing for $p_{S}$ less than

$$
p_{S}^{*}=\frac{1+(\beta-\alpha) p_{N}-\alpha\left(v_{P}-t_{P}-s_{P}\right)}{2 \alpha},
$$


and decreasing if $p_{S}$ is larger than $p_{S}^{*}$. As a consequence, the maximum value is obtained at $\operatorname{BR}_{P}\left(p_{N}\right)=\max \left(0, p_{S}^{*}\right)$, hence the proposition.

Similarly, we can look at the best response of the network provider $N$ (in the following, we suppose that the transport price towards the free content provider is always set so as to recover at least the pertaining OPEX). We can identify three different cases, depending on the values of the upper bounds $p_{N}^{P}$ and $p_{N}^{F}$.

Proposition 2. The best-response function $B R_{N}$ of network provider $N$ is one of the following values:

Case $1\left(p_{N}^{P} \leq 0\right)$

The best response function is

$$
B R_{N}\left(p_{S}\right)=\max \left(0, \frac{1+\hat{\beta} p_{S}-(\hat{\alpha}-\hat{\beta})\left(t_{F}-n_{F}\right)}{2(\hat{\alpha}-\hat{\beta})}\right) .
$$

Case $2\left(0<p_{N}^{P} \leq p_{N}^{F}\right)$

The best response function is the value of $p_{N}$ yielding the largest profit between the two alternatives

$\min \left(p_{N}^{P},\left.\frac{p_{N}^{F}-t_{F}+n_{F}+\frac{D_{0, P}}{D_{0, F}} \frac{\alpha-\beta}{\hat{\alpha}-\hat{\beta}}\left(p_{N}^{P}-t_{P}+n_{P}\right)}{2\left(1+\frac{D_{0, P}}{D_{0, F}} \frac{\alpha-\beta}{\hat{\alpha}-\hat{\beta}}\right)}\right|_{+}\right)$.

and

$$
\max \left(p_{N}^{P}, \frac{1+\hat{\beta} p_{S}-(\hat{\alpha}-\hat{\beta})\left(t_{F}-n_{F}\right)}{2(\hat{\alpha}-\hat{\beta})}\right) .
$$

Case $3\left(0<p_{N}^{F} \leq p_{N}^{P}\right)$

The best response function is the value of $p_{N}$ yielding the largest profit between the two alternatives

$$
\min \left(p_{N}^{F},\left.\frac{\left.p_{N}^{F}-t_{F}+n_{F}+\frac{D_{0, P}}{D_{0, F}} \frac{\alpha-\beta}{\hat{\alpha}-\hat{\beta}}\left(p_{N}^{P}-t_{P}+n_{P}\right)\right)}{2\left(1+\frac{D_{0, P}}{D_{0, F}} \frac{\alpha-\beta}{\hat{\alpha}-\hat{\beta}}\right)}\right|_{+}\right) .
$$

and

$$
\max \left(p_{N}^{F}, \frac{1-\alpha p_{S}-(\alpha-\beta)\left(t_{P}-n_{P}\right)}{2(\alpha-\beta)}\right) .
$$

where we have used the notation $\left.x\right|_{+}=\max (x, 0)$.

Proof: In order to determine the value $p_{N}$ that maximizes the profit of $N$,

$$
\begin{aligned}
\Pi_{N}= & a-k+p_{N}\left(D_{F}+D_{P}\right)+ \\
& \left(t_{P}-n_{P}\right) D_{P}+\left(t_{F}-n_{F}\right) D_{F},
\end{aligned}
$$

we first need to look at the conditions under which both demands $D_{P}$ and $D_{F}$ are positive. We know that $D_{P}>0$ iff $p_{N}<p_{N}^{P}$, and $D_{F}>0$ iff $p_{N}<p_{N}^{F}$.

Noting that $p_{N}^{F}>0$, we then have to consider the three possibilities on the sign of $p_{N}^{P}$ and the relative values of $p_{N}^{F}$ and $p_{N}^{P}$ :

\section{Case 1.}

If $p_{N}^{P} \leq 0$ : we have $D_{P}=0$ and $\Pi_{N}=a-k+p_{N} D_{F}+$ $\left(t_{F}-n_{F}\right) D_{F}$. Differentiating with respect to $p_{N}$ on $\left[0, p_{N}^{F}\right]$, we have

$$
\frac{\partial \Pi_{N}}{\partial p_{N}}=D_{0, F}\left(1+\hat{\beta} p_{S}-(\hat{\alpha}-\hat{\beta})\left(2 p_{N}+t_{F}-n_{F}\right)\right) .
$$

Remark that this derivative becomes 0 when

$$
\begin{aligned}
p_{N} & =p_{N}^{*}=\frac{1+\hat{\beta} p_{S}-(\hat{\alpha}-\hat{\beta})\left(t_{F}-n_{F}\right)}{2(\hat{\alpha}-\hat{\beta})} \\
& =\frac{1+\hat{\beta} p_{S}}{2(\hat{\alpha}-\hat{\beta})}-\frac{t_{F}-n_{F}}{2}
\end{aligned}
$$

which is less than $p_{N}^{F}$ if $t_{F}>n_{F}$. As a consequence, we get

$$
\operatorname{BR}_{N}\left(p_{S}\right)=\max \left(0, \frac{1+\hat{\beta} p_{S}-(\hat{\alpha}-\hat{\beta})\left(t_{F}-n_{F}\right)}{2(\hat{\alpha}-\hat{\beta})}\right) \text {. }
$$

\section{Case 2.}

If $0<p_{N}^{P} \leq p_{N}^{F}$ : then for $p_{N} \in\left[0, p_{N}^{P}\right), D_{P}, D_{F}>0$ while for $p_{N} \in\left[p_{N}^{P}, p_{N}^{F}\right)$, only $D_{F}>0$. We need to look at those two intervals separately. On $\left[0, p_{N}^{P}\right)$, the derivative is

$$
\begin{aligned}
\frac{\partial \Pi_{N}}{\partial p_{N}}= & D_{0, F}\left(1-\hat{\alpha} p_{N}+\hat{\beta}\left(p_{S}+p_{N}\right)\right)+ \\
& D_{0, P}\left(1-\alpha\left(p_{S}+p_{N}\right)+\beta p_{N}\right)+ \\
& \left(p_{N}+t_{P}-n_{P}\right) D_{0, P}(\beta-\alpha)+ \\
& \left(p_{N}+t_{F}-n_{F}\right) D_{0, F}(\hat{\beta}-\hat{\alpha}) .
\end{aligned}
$$

Recalling the expressions (6) and (4) for the upper bounds on the price, the price zeroing the above derivative can be expressed as

$$
p_{N}^{*}=\frac{\left.p_{N}^{F}-t_{F}+n_{F}+\frac{D_{0, P}}{D_{0, F}} \frac{\alpha-\beta}{\hat{\alpha}-\hat{\beta}}\left(p_{N}^{P}-t_{P}+n_{P}\right)\right)}{2\left(1+\frac{D_{0, P}}{D_{0, F}} \frac{\alpha-\beta}{\hat{\alpha}-\hat{\beta}}\right)} .
$$

The optimal value on this interval is then

$\mathrm{BR}_{N}\left(p_{S}\right)=$

$$
\min \left(p_{N}^{P},\left.\frac{p_{N}^{F}-t_{F}+n_{F}+\frac{D_{0, P}}{D_{0, F}} \frac{\alpha-\beta}{\hat{\alpha}-\hat{\beta}}\left(p_{N}^{P}-t_{P}+n_{P}\right)}{2\left(1+\frac{D_{0, P}}{D_{0}, F} \frac{\alpha-\beta}{\hat{\alpha}-\hat{\beta}}\right)}\right|_{+}\right) .
$$

On $\left[p_{N}^{P}, p_{N}^{F}\right), D_{P}=0$ and $D_{F}>0$ and we are back to Case 1 , but with a restricted interval, leading to an optimal value on this interval

$$
\operatorname{BR}_{N}\left(p_{S}\right)=\max \left(p_{N}^{P}, \frac{1+\hat{\beta} p_{S}-(\hat{\alpha}-\hat{\beta})\left(t_{F}-n_{F}\right)}{2(\hat{\alpha}-\hat{\beta})}\right) .
$$

After obtaining the solutions for the two subcases, we will retain the price yielding the larger profit for the network provider.

\section{Case 3.}

If $0<p_{N}^{F} \leq p_{N}^{P}$, we have the same situation as in Case 2, but with reversed role for the two demands.

When $p_{N} \in\left[0, p_{N}^{F}\right)$, we have $D_{P}, D_{F}>0$. The best response is

$$
\begin{aligned}
& \operatorname{BR}_{N}\left(p_{S}\right)= \\
& \min \left(p_{N}^{F},\left.\frac{p_{N}^{F}-t_{F}+n_{F}+\frac{D_{0, P}}{D_{0, F}} \frac{\alpha-\beta}{\hat{\alpha}-\hat{\beta}}\left(p_{N}^{P}-t_{P}+n_{P}\right)}{2\left(1+\frac{D_{0, P}}{D_{0, F}} \frac{\alpha-\beta}{\hat{\alpha}-\hat{\beta}}\right)}\right|_{+}\right) .
\end{aligned}
$$


Instead, when $p_{N} \in\left[p_{N}^{F}, p_{N}^{P}\right)$, the demand for free content zeroes, and the best response becomes

$$
\operatorname{BR}_{N}\left(p_{S}\right)=\max \left(p_{N}^{F}, \frac{1-\alpha p_{S}-(\alpha-\beta)\left(t_{P}-n_{P}\right)}{2(\alpha-\beta)}\right) .
$$

Again, after obtaining the solutions for the two subcases, we will retain the price yielding the larger profit for the network provider.

This concludes the proof.

\section{EQUILIBRIUM RETAIL PRICES}

In Section III we have derived the best response functions. The intersection of the best response functions provides us with the Nash equilibrium solution of the game. In this section we explore what happens in a sample scenario, under both neutrality and non-neutrality conditions. Namely, we investigate the existence and uniqueness of Nash equilibria, the impact of wholesale price on the retail price offered to the customer and on the providers' profits.

\section{A. A sample scenario}

We want to study the behaviour of the pay-per-use content provider and of the network provider when the network provider acts on the transport unit prices $t_{F}$ and $t_{P}$. By acting on those prices, the network provider may exhibit a non-neutral standing towards the two content providers. Namely, when $t_{F}=t_{P}$, we label its behaviour as neutral. Instead, when $t_{F} \neq t_{P}$, its price decision favours either of the two contenders: a higher price for the free content provider $\left(t_{F}>t_{P}\right)$ benefits the pay-per-use content provider, and vice versa. We can explore the full range of situations by moving in the $t_{P}-t_{F}$ plane, having set all the other parameters, with $t_{F}=\lambda t_{P}(\lambda=1$ case corresponds to the neutral behaviour $)$.

In order to analyse those issues, we have set the values for the other parameters by gathering data on the current market conditions. Namely, in the following we have used the values reported in Table I, based on data extracted from the Annual Report of the Italian Communication Regulatory Authority (AGCOM) [1].

As to transport unit prices $t_{F}$ and $t_{P}$, we have set a range of variation $[0,0.5] € / \mathrm{GB}$, which includes the case of free transport as a limit situation.

\section{B. Neutrality}

We start by examining what happens under neutral price setting by the network provider. We therefore set $t_{F}=t_{P}$ and let them vary together from the maximum value 0.5 down to free transport. Under all values of the two transport prices, the pricing game between $N$ and $P$ exhibits a single equilibrium.

The corresponding equilibrium prices $p_{S}$ and $p_{N}$ are shown in Fig. ??. Changing the transport price has an opposite impact on the two equilibrium prices. When the transport price lowers, the price set by the pay-per-use content provider lowers as well, as a result of the diminished pressure by the network provider, which, on the other hand, must increase its retail price to compensate for the lowered wholesale revenue.

\begin{tabular}{lc}
\hline$D_{0, P}\left[\frac{\mathrm{GB}}{\mathrm{month}}\right]$ & 31.5 \\
$D_{0, F}\left[\frac{\mathrm{GB}}{\mathrm{month}}\right]$ & 19 \\
$a\left[\frac{€}{\mathrm{~GB}}\right]$ & 10 \\
$v_{F}\left[\frac{€}{\mathrm{~GB}}\right]$ & 0.15 \\
$v_{P}\left[\frac{€}{\mathrm{~GB}}\right]$ & 0.15 \\
$s_{F}\left[\frac{€}{\mathrm{~GB}}\right]$ & 0.15 \\
$s_{P}\left[\frac{€}{\mathrm{~GB}}\right]$ & 0.15 \\
$n_{F}\left[\frac{€}{\mathrm{~GB}}\right]$ & 0.075 \\
$n_{P}\left[\frac{€}{\mathrm{~GB}}\right]$ & 0.125 \\
$k\left[\frac{€}{\mathrm{month}}\right]$ & 7.5 \\
$\alpha$ & 0.317 \\
$\beta$ & -0.952 \\
$\hat{\alpha}$ & 3.584 \\
$\hat{\beta}$ & 2.105 \\
\hline
\end{tabular}

TABLE I

PARAMETER VALUes

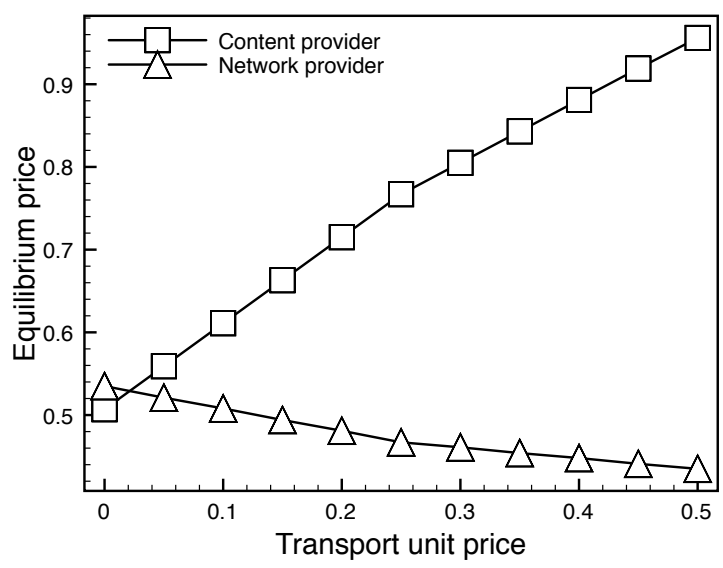

Fig. 2. Equilibrium retail prices under neutrality

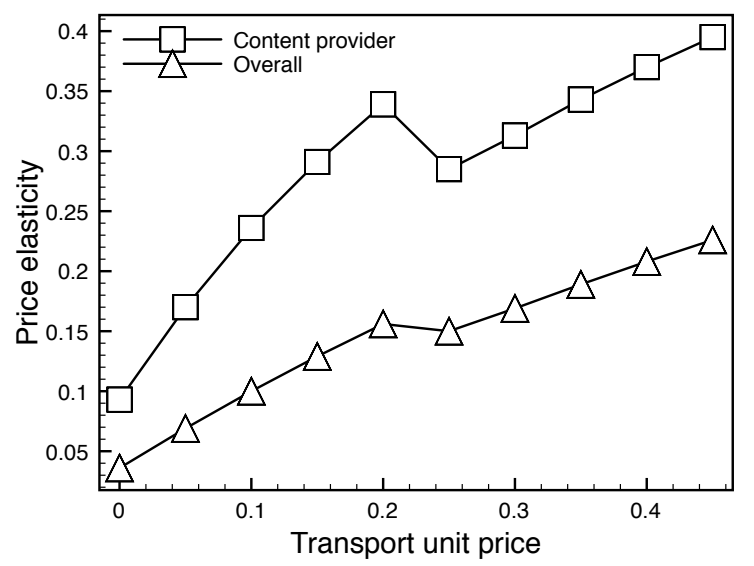

Fig. 3. Elasticity of equilibrium retail prices under neutrality 


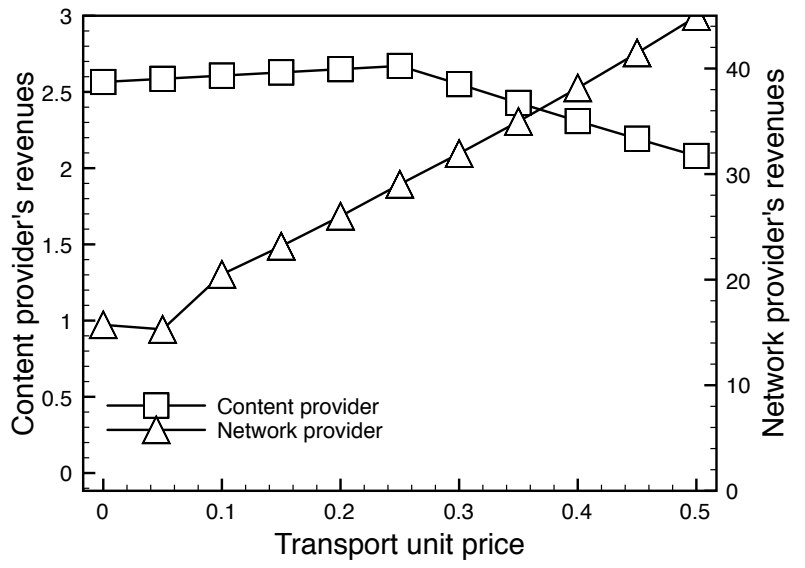

Fig. 4. Profit of providers under neutrality

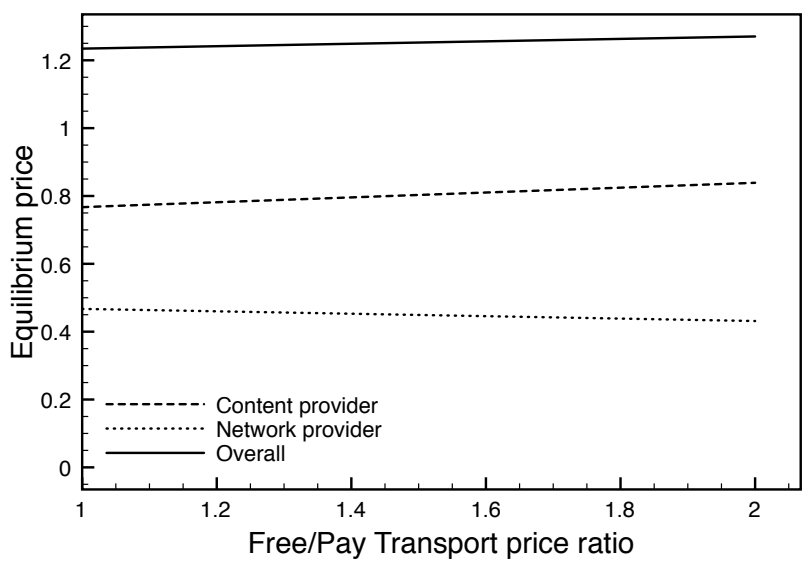

Fig. 5. Equilibrium prices with free content provider disadvantaged

Changing the transport prices impacts on the retail prices. We can evaluate the extent, by computing the elasticity of retail prices, namely, of the retail price $p_{S}$ set by the content provider and that of the overall price $p_{S}+p_{N}$ experienced by the customer. The elasticities provide us with the percentage variation in the retail price as the result of a unit percent change in the transport price:

$$
\varepsilon_{S}=\frac{t_{P}}{p_{S}} \frac{\partial p_{S}}{\partial t_{P}} \quad \varepsilon_{S+N}=\frac{t_{P}}{p_{S}+p_{N}} \frac{\partial\left(p_{S}+p_{N}\right)}{\partial t_{P}} .
$$

We can evaluate both expressions numerically as we lower the transport unit price. The results are shown in Fig. 2 and Fig. 3. Both values are way below unity, meaning in terms of transfer of price reduction: for the range of transport price examined, for each percent reduction in the transport price, the overall retail price paid by the customer decreases by no more than 0.2 percent roughly. The benefit of transport price reductions is largely retained by the content provider.

We now consider the impact of transport price changes on the providers' profit. In Fig. 4, the network provider's profit falls linearly as the transport prices decrease. The content

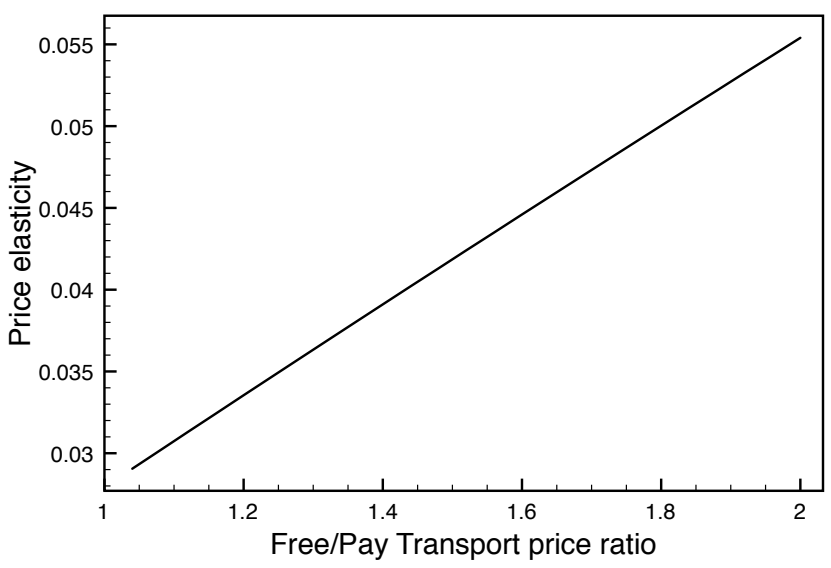

Fig. 6. Elasticity of the retail price with free content provider disadvantaged

provider benefits from that reduction, but not over the whole range of variation: when the transport unit price gets below the 0.3 value, the profit of the content provider stays fairly constant.

\section{Non neutrality}

We now turn to the case where the network provider takes a non-neutral stance. In particular, we examine here the case of prices favourable to the pay-per-use content provider. We set $t_{P}=0.25$ (halfway the range of variation we have assumed) and let the transport price ratio $\lambda$ vary between 1 and 2 . The free content provider is progressively cornered as the transport price $t_{F}$ increases.

For all values considered, the game exhibits a single equilibrium. The resulting prices are shown in Fig. 5. Though the payper-use provider is not directly affected by the price paid by the free content provider, the price it asks its customers grows slightly. This is compensated for by the expected decrease in the price the network provider asks the customers (the payments from the free content provider to the network provider increase). The overall effect on the customer is negligible: the price $p_{S}+p_{N}$ paid by the customer increases by less than $3 \%$ when the transport price $t_{F}$ doubles from 0.25 to 0.5 . This is confirmed by the elasticity of the total price $p_{S}+p_{N}$, shown in Fig. 6. Both the network provider and the pay-peruse content provider benefit from the increased transport prices suffered by the free content provider. The network provider's profit increases due to the increased $t_{F}$ price; the pay-peruse content provider reaches a more convenient equilibrium at higher $p_{S}$ prices. As the price ratio $t_{F} / t_{P}$ increases, the profits of both providers grow linearly, as shown in Fig. 7. Since both providers benefit from cornering the free content provider, the danger of collusion exists and should be investigated.

\section{CONCLUSION}

We have examined the issue of a non-neutral approach by the network provider towards content providers offering their services respectively free of charge and on a pay-per-use basis. 


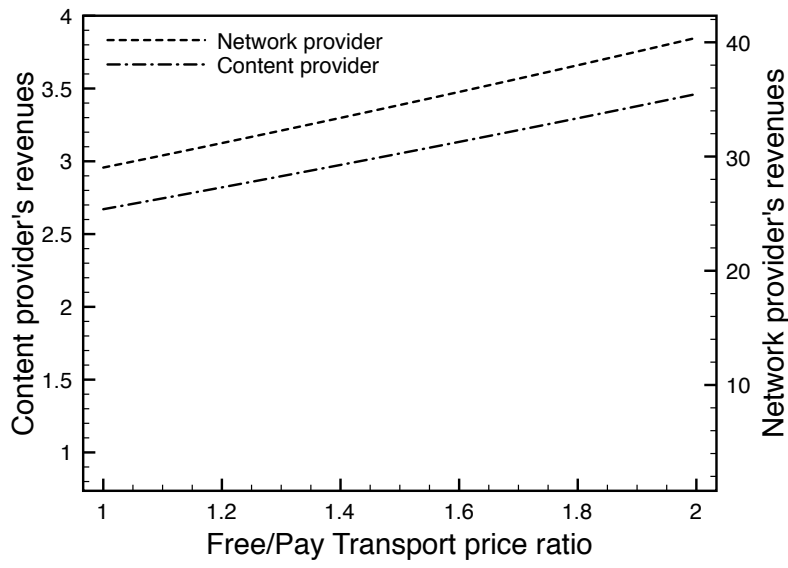

Fig. 7. Profits with free content provider disadvantaged

We have formulated and solved the game between the network provider and the pay-per-use provider, when both use the retail price charged to the end customer. When the network provider charges the two content providers with equal wholesale prices, we find that just a small portions of the wholesale price reductions is transferred to the end customer. In the nonneutral case, when the network provider discriminates against the free content provider by charging it more, the profits of both the network provider and the pay-per-use content provider grow, while the retail price increases (though by a small amount). A non-neutral approach appears to spur collusive behaviour, with no benefit at all for the end customer.

\section{ACKNOWLEDGMENT}

This work has been funded by the INNIS project in the Euro-NF Network of Excellence. The support of INRIA's cooperative research action MENEUR and CAPTURES ANR project is also acknowledged for the French authors.

\section{REFERENCES}

[1] Autorità per le garanzie nelle comunicazioni AGCOM (Italian Communications Regulatory Authority), "Annual report," 2011, available at http://www.agcom.it.

[2] G. Allon and A. Federgruen, "Service competition with general queueing facilities," Operations Research, vol. 56, no. 4, pp. 827-849, Jul 2008.

[3] BEREC, "BEREC guidelines on net neutrality and transparency: Best practices and recommended approaches," Body of European Regulators for Electronic Communications (BEREC), Tech. Rep., October 2011.

[4] F. Boussion, P. Maillé, and B. Tuffin, "Net neutrality debate: Impact of competition among ISPs," in Proceedings of the Fourth International Conference on COMmunication Systems and NETworkS (COMSNETS), Bangalore, India, 2012.

[5] C. Courcoubetis and R. Weber, Pricing Communication Networks: Economics, Technology and Modelling (Wiley Interscience Series in Systems and Optimization). John Wiley \& Sons, 2003.

[6] R. Ma, D.-M. Chiu, J. Lui, V. Misra, and D. Rubenstein, "Interconnecting eyeballs to content: A Shapley value perspective on ISP peering and settlement," in Proceedings of the International Workshop on Economics of Networked Systems (NetEcon), 2008, pp. 61-66.

[7] _ "On cooperative settlement between content, transit and eyeball internet service providers," in Proceedings of the ACM International Conference on Emerging Networking EXperiments and Technologies (CoNEXT), 2008.

[8] P. Njoroge, A. Ozdaglar, N. Stier-Moses, and G. Weintraub, "Investment in two sided markets and the net neutrality debate," Columbia University, Decision, Risk and Operations Working Papers Series, Tech. Rep. DRO2010-05, 2010

[9] M. Osborne and A. Rubinstein, A Course on Game Theory. MIT Press, 1994.

[10] A. Parker and S. Pignal, "Push to end content providers free lunch," Financial Times, 13 February 2011, available at http://www.ft.com.

[11] Sandvine, "Global internet phenomena report," Spring 2011. 